\title{
To Russia, for Math
}

\section{Andrei Okounkov and Stanislav Smirnov}

Note: The opinions expressed here are not necessarily those of Notices.

The St. Petersburg ICM is rapidly approaching, and soon its foreign participants will be planning their trips to Russia. The ICM Local Organizing Committee felt that, at this important moment, mathematicians in many countries might receive very one-sided information about Russian mathematics in general, and preparations for the Congress in particular. We thought that it would be good for our foreign colleagues to hear directly from the chairs of Russian mathematical centers, institutes, departments, societies, etc. We thus sent out a questionnaire asking people to respond to questions about the importance of international cooperation, the meaning of the ICM to young mathematicians in Russia, the impact of satellite events on the development of mathematics across the Russian Federation, and the level of interest in mathematics among Russian university and secondary school students. We also asked people to specifically address foreign colleagues planning to come to the ICM, and those calling for a boycott of the ICM.

We strongly encourage the readers of the Notices to read the complete responses at https: //www . math . columbia . edu/ okounkov/To\%20Russia,\%20For\%20Math. pdf. You will hear the voices of people who are preserving Russian mathematical traditions, who are building the future of Russian mathematics, and who are educating the next generation of Russian mathematicians. There is great power

Andrei Okounkov is Samuel Eilenberg Professor of Mathematics at Columbia University and teaches mathematics at Skoltech and Higher School of Economics in Moscow. His email address is okounkov@math.columbia .edu.

Stanislav Smirnov is a professor of mathematics at the Université de Genève, and also is part-time at Skoltech and St. Petersburg University. His email address is stanislav. smi rnov@unige.ch.

For permission to reprint this article, please contact: reprint-permission aams.org.

DOI: https://dx.doi.org/10.1090/noti 2307 and great diversity in what they say. No collection of quotes will do justice to their complete responses. Please consider the following collection of quotes as an emphatic invitation to read the original.

On the importance of international cooperation, Igor Krichever shares the following memory: "The first international conference in which I was allowed to participate was the first Soviet-American conference on Soliton Theory held in 1979 in Kiev. Two weeks of almost round-the-clock (we all stayed in the same hotel) talks about mathematics with great mathematicians and physicists: Gelfand, Sagdeev, Mark Kac, McKean, Lax, Novikov, Zakharov, Kruskal, and others. Ideas for many of my papers were born then." Yuri Matiyasevich echoes this: "I was fortunate to participate in the Moscow Congress of 1966, which was the first and so far the only International Congress of Mathematicians that took place in my country. I was a sophomore at the time, just getting my first meaningful results. The opportunity to see the great foreign mathematicians (in my case, Kleene, Tarski, and Henkin) made a huge and inspiring impression on me, and I continued to work even more diligently on Hilbert's 10-problem (which, by the way, was formulated at the Paris Congress of 1900)."

Victor Vassiliev makes another important point: "A great problem of our life (in particular of the scientific one) is the trend towards isolation, promoted (besides our own inertia) by too many influential people who cannot accept free competition in accordance with the international standards, or do not like openness and transparency, or for whom confrontation is their only natural business. Opening the borders, creating scientific ties and collaborations, free exchange of information, fixing a proper image of contemporary scientific life in the minds of our beginners-these are my hopes for this event." And then he adds: "Closing the doors would increase the stink in our room." 
On what the ICM will mean for young mathematicians in Russia, Sergei Ivanov writes: "We are in St. Petersburg, the ICM venue, and we have over 200 math students at our bachelor and master programmes. They are strong and motivated students, many of them are eager to attend conferences and lectures by visiting professors. Some of them are preparing to volunteer at the ICM, most are anticipating great lectures where they can learn new ideas and inspiration."

This question very much resonates with another question about the interest in mathematics among Russian students. Daud Mamiy writes: "In Russia, students' interest in mathematics is traditionally high. Millions of schoolage children take part in the All-Russian Olympiad of School Children in Mathematics and other mathematical Olympiads and competitions. The system for identifying mathematically gifted children and further developing their abilities has a long-standing tradition in Russia, dating back to the 30s of the twentieth century. Various forms of conducting mathematical competitions in Russia are in many cases unique and may be of interest to colleagues from other countries. Innovative methods of teaching mathematics have been created and developed over many decades, and they can also be very interesting."

Russia is a country spanning 11 time zones, and it is important to consider the effect the ICM will have far away from St. Petersburg, through satellite events of the Congress. All of our respondents wrote about this. For example, Olga Pochinka writes about the "Dynamical Systems: Theory and Applications" satellite conference that will take place in Nizhny Novgorod, and will include a school for young scientists. Her colleague Alexandra Skripchenko, from the Higher School of Economics in Moscow, writes: "The members of our Faculty of Mathematics participate in the organization of seven satellite conferences, six of which will be held at least partially at the HSE. We hope for interesting talks and productive discussions during breaks, in which not only established mathematicians, but also fledgling mathematicians, will be able to take part. We also hope that those of our guests who rarely visit Russia will enjoy Moscow and, of course, our Faculty of Mathematics, so that they will want to come to us regularly."

Sergei Kislyakov writes about nine satellite conferences that are being planned at the Euler Institute. His colleague across town, Maxim Pratusevich, writes about the special satellite conference for mathematical education organized at St. Petersburg Lyceum 239.

Lyceum 239 is one of the top high schools for mathematics in Russia, whose graduates include Grigory Perelman. Another high school for mathematics is the School No. 2 in Moscow. Its director Mikhail Sluch writes the following about the role of mathematics in Russian education: "We, the mathematical educators of Russia, treat mathematical science with great respect. Many people understand that it is mathematics that underlies the achievements in high-tech areas that the country would like to be proud of, and which put it among the leading countries in the world." And then he adds: "Also, many representatives of Russian society traditionally have a strong desire to develop their own judgments, to analyze - a natural response to the dominance of a certain ideology for many decades. In this regard, people are very attentive to the tools that allow them to make such judgments. And these certainly include mathematics."

We conclude with some quotes addressed directly to our foreign colleagues. Dmitry Treschev writes: "If you visit St. Petersburg, then in addition to the participation in a great mathematical celebration you will have the possibility to compare images of Russia given by mass media and social networks with reality. I expect, surprises await you."

Daud Mamiy: "Dear friends and colleagues! Russia as a whole and the entire Russian mathematical community are waiting for you at the Congress. We want to show you the beauty and diversity of the regions of our country, to show you our hospitality. The Caucasus Mathematical Olympiad held by Adygea State University is held under the slogan "Caucasus without Borders" and is an example of how mathematics can unite students from the Black Sea region and the Caucasus region, torn by political contradictions and conflicts. Mathematicians have always been an example of how to cooperate, be friends, and communicate regardless of political circumstances and events. Boycotting has never been an effective way to solve problems. Examples of this are the Olympic Games in Moscow and Los Angeles in 1980 and 1984. We are waiting for you in Russia, we are waiting for you in the Caucasus, we are waiting for you in Adygea."

Igor Krichever: "I know that there are those who are calling for a boycott of the Congress because of violations of basic human rights in Russia. I agree that today's political landscape in Russia is dire. If I am in Moscow, I always take part in protest rallies. But I strongly disagree with the calls for a boycott of Congress. It will be counterproductive. At the political level, it will be just another protest, but it will be a severe blow to mathematical life in Russia. There is a toast in Russia: let's drink to the success of our hopeless cause. Possibly, the desire to foster next generations of young mathematicians in Russia who will enrich the world community is just as hopeless as the struggle for an ideal world and human rights in it. But it is worth doing both instead of counterposing the two."

Igor Rubanov: "I, like you, am outraged by the unjust sentence of Azat Miftakhov, whom I know as a former student of the Kirov Summer School. But many examples show that a boycott of the Congress will not help the release of Azat, nor will it help to achieve progress on other issues. The Russian authorities may even be pleased with another argument that helps them portray Russia as a "besieged fortress." The Russian mathematical community will suffer a significant loss. Does it deserve such a punishment for 
the sins of those in power? Think about it-and then do as your conscience tells you."

Alexandra Skripchenko: "I understand and respect the position of people who are concerned about the politics, the situation with human rights, and consider the fact of their participation or non-participation in scientific events as a certain political statement. However, I cannot share this position. It seems to me that direct interaction is always the most effective. The ICM attracts a large number of young researchers from developing countries, where the mathematical culture is still being formed. Who they meet at the ICM will very much determine what this world will look like in the near future. I believe in personal communication and its role both in mathematical discoveries and in spreading the ideas of humanism. Come visit us!"

Olga Pochinka: "St. Petersburg, where the Congress is held, and the Russian cities that host satellite conferences, are located in very beautiful places and have beautiful modern and historical architecture, and the Russian people are very hospitable. In addition to the exchange of professional information, a trip to Russia will surely be a source of inspiration and a lot of positive emotions."

Sergei Ivanov: "Welcome to St. Petersburg! The ICM is a good occasion to visit this beautiful city and its many tourist attractions. It is hard to comment on the political campaign against the ICM. The logic of linking mathematics to politics is beyond my understanding."

Maxim Pratusevich: "As the 2018 FIFA World Cup has shown, Russia is a hospitable country with a lot to see. St. Petersburg is charming in the summer, and guests, in addition to the events of the Congress, will have a great opportunity to see St. Petersburg and its surroundings. I am confident that the Congress will promote productive, mutually beneficial, and respectful communication among mathematicians of the whole world."

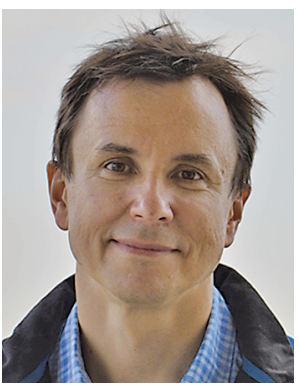

Andrei Okounkov

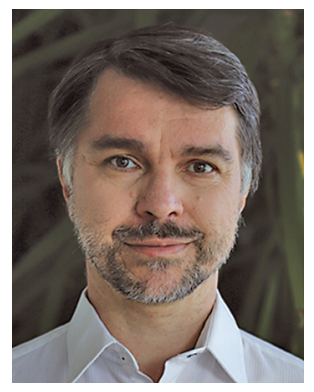

Stanislav Smirnov
Credits

Photo of Andrei Okounkov is courtesy of Andrei Okounkov. Photo of Stanislav Smirnov is courtesy of Nikolay Smirnov.

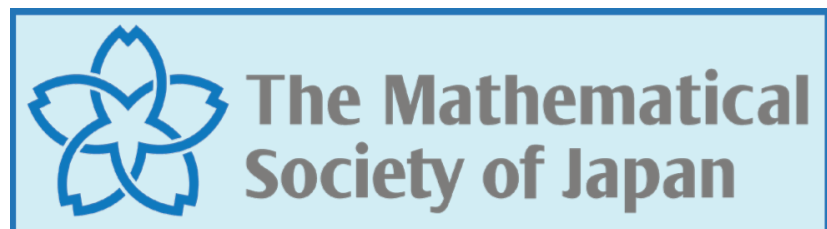

\section{Recent volumes from MSJ}

\section{Advanced Studies \\ in Pure Mathematics \\ http://mathsoc.jp/publication/ASPM/}

Volume 86

\section{Development of Iwasawa \\ Theory \\ --- the Centennial of \\ K. Iwasawa's Birth}

Edited by M. Kurihara,

K. Bannai, T. Ochiai,

T. Tsuji

ISBN 978-4-86497-092-1

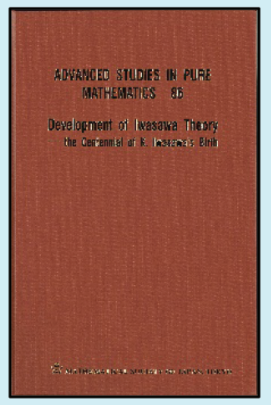

Volume 85

The Role of Metrics in the Theory of Partial Differential Equations

Edited by Y. Giga, N. Hamamuki, H. Kubo,

H. Kuroda, T. Ozawa

ISBN 978-4-86497-090-7

MSJ Memoirs

http://mathsoc.jp/publication/memoir/memoirs-e.html

Volume 39

Traveling Front Solutions in Reaction-Diffusion

Equations

Masaharu Taniguchi

ISBN 978-4-86497-097-6

Volume 38

Moduli spaces of real projective structures on surfaces

Alex Casella, Dominic Tate, Stephan Tillmann ISBN 978-4-86497-096-9

$\nabla \nabla \nabla$ For purchase, visit $\nabla \nabla \nabla$ http://www.ams.org/bookstore/aspmseries http://www.worldscientific.com/series/aspm https://www.worldscientific.com/series/msjm

The Mathematical Society of Japan 34-8, Taito 1-chome, Taito-ku

Tokyo, JAPAN www.mathsoc.jp/en/ 